\title{
MAGNETIC RESONANCE STUDIES OF PHOTO-INDUCED ELECTRON TRANSFER REACTIONS
}

PROGRESS REPORT

FOR PERIOD JUNE 1, 1991 - MAY 31, 1992

\author{
HANS VAN WILLIGEN \\ UNIVERSITY OF MASSACHUSETTS AT BOSTON \\ BOSTON, MASSACHUSETTS 02125
}

JANUARY 1992

PREPARED FOR

THE UNITED STATES DEPARTMENT OF ENERGY

AGREEMENT NO. DE-FG02-84ER13242

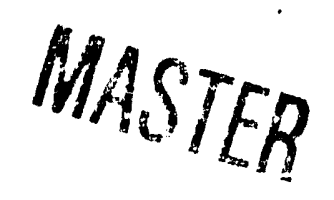

TRIBUTION OF THIS DOCUMENT IS UNLIMITED 


\section{DISCLAIMER}

This report was prepared as an account of work sponsored by an agency of the United States Government. Neither the United States Government nor any agency thereof, nor any of their employees, makes any warranty, express or implied, or assumes any legal liability or responsibility for the accuracy, completeness, or usefulness of any information, apparatus, product, or process disclosed, or represents that its use would not infringe privately owned rights. Reference herein to any specific commercial product, process, or service by trade name, trademark, manufacturer, or otherwise does not necessarily constitute or imply its erdorsement, recommendation, or favoring by the United States Government or any agency thereof. The views and opinions of authors expressed herein do not necessarily state or reflect those of the United States Government or any agency thereof. 


\section{IN'TROD ISTION}

During the past year research has focused on the application of Fourier Transform Electron Paramagnetic Resonance (FT EPR) in the study of photo-induced electron transfer reactions. In FT EPR a microwave pulse rotates the electron spin magnetization vector from the $\mathrm{z}$ (magnetic field) axis into the $\mathrm{xy}$ plane $(\pi / 2$ pulse). Then the time evolution of the magnetization in the $x y$ plane, the free induction decay (FID), is sampled. The Fourier transform of the FID gives the frequency domain EPR spectrum of the free radicals present in the sample.

FT EPR is ideally suited for time-resolved studies of free radicals generated by pulsedlaser excitation. This is because the FID only reports on species present at the time of the $\pi / 2$ pulse. It has been found that formation and decay of free radicals can be monitored by measuring spectra for delay times between laser and microwave pulses extending from the nanosecond to the millisecond time domain. Thus FT EPR measurements can give reliable information on chemical rate constants. In addition, it can give data that may not be accessible with other spectroscopic methods:

1. The high spectral resolution makes it possible to identify paramagnetic species unambiguously. Solvation effects are easily detected and can give information on the environment.

2. The time development of the spectra, generally, is determined in part by Chemically Induced Dynamic Electron Spin Polarization (CIDEP) mechanisms. Analysis of CIDEP effects contributes to the understanding of reaction mechanisms.

3. Signal contributions from radical pairs can be identified. Measurement of the kinetics of formation and decay of these species can give an insight, at the molecular level, into substituent and medium effects on their characteristics.

4. Information on spin-lattice relaxation $\left(T_{1}\right)$ and linewidth $\left(T_{2}\right)$ can be derived. These parameters reflect the molecular motion of the free radicals.

In the studies carried out, porphyrins were used as excited state electron donors and quinones were used as acceptor molecules. These molecules were chosen because of their favorable photochemical and photophysical characteristics, and the possibility that they may be suitable for application in man-made solar energy conversion devices. The objective of the investigations is to contribute to the understanding of the factors that affect the efficiency of the electron transfer reactions. 
The work has been concerned with the following topics:

I. The FT EPR study of benzoquinone anion $\left(\mathrm{BQ}^{-}\right)$radicals generated by pulsed-laser induced electron tranfer from zinc tetraphenylporphyrin (ZnTPP) or tetra-sulfonated ZnTPPP (ZnTPPS) in homogeneous solution.

II. The FT EPR study of photo-induced electron transfer from ZnTPP (or ZnTPPS) to duroquinone (DQ) in micellar solutions.

III. The FT EPR study of photochemical reactions involving reactants adsorbed on silica gel. 


\section{RESULTS}

\section{Electron transfer in homogeneous solutions}

A complete analysis was made of the time evolution of the FT EPR spectra from $\mathrm{BQ}^{-}$ formed in the reactions:

$$
\mathrm{ZnTPP}+\mathrm{BQ} \stackrel{\mathrm{h} \nu}{\longrightarrow} \mathrm{ZnTPP}^{+}+\mathrm{BQ}^{-}
$$

and

$$
\mathrm{ZnTPPS}+\mathrm{BQ} \stackrel{\mathrm{h} \nu}{\longrightarrow} \mathrm{ZnTPP}^{+}+\mathrm{BQ}^{-}
$$

The time domain covered by the spectra extended from the nanosecond to the millisecond time domain. The solvent used for the study of the ZnTPP/BQ system was ethanol. $\mathrm{ZnTPPS} / \mathrm{BQ}$ was studied in a series of water/ethanol solvent mixtures.

It proved possible to distinguish the effect of radical formation and decay on the signal development from the CIDEP and spin relaxation contributions. As a consequence, the spectral data could be used to get information on the effect of solvent composition on the electron transfer rate constant. It was found that the time evolution of the radical pair CIDEP signal contributions is affected by the homogeneous electron transfer reaction

$$
\mathrm{BQ}+\mathrm{BQ}^{-} \rightarrow \mathrm{BQ}^{-}+\mathrm{BQ}
$$

This reaction also makes a contribution to the linewidth of the resonance peaks. These effects have been used to determine the rate constant of homogeneous electron transfer.

The rate constant of the photo-induced electron transfer from $\mathrm{ZnTPP}(\mathrm{S})$ to $\mathrm{BQ}$ was found to be inversely proportional to solvent viscosity. From this it is concluded that the reaction is diffusion controlled. The rate constant of $\mathrm{BQ}^{-}$formation shows a $\mathrm{BQ}$ concentration dependence characteristic for a diffusion controlled reaction.

The introduction of the $\mathrm{SO}_{3}^{-}$groups in the porphyrin does not affect the forward electron transfer process. By contrast, the rate of the back electron transfer is reduced markedly by the introduction of the anionic groups. Apparently, reactive encounters between $\mathrm{BQ}^{-}$and $\mathrm{ZnTPPS}^{+}$(which carries three negative charges) are inhibited by electrostatic repulsion. It is noteworthy, however, that the repulsion does not appear to affect the radical pair CIDEP contribution. Measurements of $\mathrm{BQ}^{-}$formed by electron transfer from $\mathrm{ZnTPPS}$ in $100 \%$ water gave poor results. Fluorescence spectra established that this is due to ground state complexation between donor and acceptor molecules. 


\section{Electron transfer in micellar solutions}

Photo-induced electron transfer reactions in micellar solutions have been subject of numerous studies in recent years. The interest in these systems stems in part from the potential relevance to applications in conversion and storage of solar energy. Also, the investigations contribute to the understanding of the factors that play a role in electron transfer across boundaries between hydrophobic and hydrophilic domains in biological systems.

The keypoint in studies of photochemical reactions in heterogeneous media with FT EPR is that the parameters that determine CIDEP signal contributions, lineshapes, and relaxation times are sensitive to the spatial distribution of reactants and products as well as molecular motion (rotation, translation). As a consequence, information derived from FT EPR spectra can contribute to the understanding of the spatial distribution and stability of reactants and products in the microheterogeneous environment.

The following systems were studied:

a. ZnTPP and BQ in a micellar solution of cetyltrimethylammonium chloride (CTAC), and

b. ZnTPPS and DQ in micellar solutions of sodium dodecylsulfate (SDS), triton X100 (TX100), and CTAC.

FT EPR spectra of the quinone anion radicals $\left(\mathrm{BQ}^{-}\right.$or $\left.\mathrm{DQ}^{-}\right)$, formed by electron transfer from the porphyrins, were measured as function of delay time between laser pulse and $\pi / 2$ microwave pulse.

The results of our study has established that FT EPR can provide information that cannot be derived from data provided by optical spectroscopy. For instance, in TX100 electron transfer takes place between donor ( $\mathrm{n}$ TPPS) and acceptor (DQ) molecules that are associated with the micelles. After electron transfer, the anion radical escapes into the aqueous phase within a few tens of nanoseconds judging from the linewidth of the hyperfine components in the EPR spectrum. By contrast, in CTAC electrostatic attraction between the cationic headgroups of the surfactant molecules and the negatively charged electron transfer products generates long-lived $(\sim 5 \mu s)$ radical pairs. The presence of the radical pairs is evident from the characteristic EPR signal produced by these species. Finally, in SDS electron transfer involves donor (ZnTPPS) and acceptor (DQ) molecules dissolved in the bulk aqueous phase. Since most of the DQ is found inside the micelles, and ZnTPPS prefers the aqueous phase, the rate of electron transfer is small. It is noteworthy that in 
TX100 and CTAC solutions, where donor and acceptor are associated with the micelles, no evidence is found for singlet excited state electron transfer. This indicates that, even though the reactants are confined to a restricted space, their average separation still exceeds the reaction radius of the excited donor molecules.

\section{Photochemistry of reactants adsorbed on silica gel}

Photochemistry involving molecules adsorbed in the pores of silicas, clays, and zeolites is of interest because the confinement of reactants and products in a restricted space will affect the reaction kinetics and mechanism in a unique way. On-going research in a number of laboratories is concerned with the design of systems in which the solid support serves to promote fast photo-induced electron transfer and inhibits the energy wasting back electron transfer reaction.

The work we hav initiated recently explores the utility of EPR measurements in monitoring the formation and decay of paramagnetic products of photochemical reactions taking place in the pores of silica gels, zeolites, and clays. In principle, spectra from time-resolved EPR measurements can give information that complements that provided by optical spectroscopy. Firstly, the high spectral resolution can be used to identify transient free radicals unambiguously. Secondly, spin relaxation and linewidth data convey information on the motion of the paramagnetic species. Finally, the spectra can be used to determine rate constants of free radical formation and decay.

With preliminary experiments we have shown that FT EPR can be used to monitor the pulser-laser induced chemistry taking place between reactants adsorbed in the pores of silica gel. One measurement involved the photo-induced electron transfer from ZnTPP to DQ. The samples were prepared by adsorption of the reactants from a solution in a non-polar solvent onto the silica gel, drying of the silica, and subsequent introduction of polar solvent molecules in the silica pores by exposing the solid to solvent saturated argon gas.

In the absence of the polar solvent molecules no EPR spectra were observed. Well resolved spectra were obtained after introduction of the solvent. The measurements are facilitated by the faut that the electron transfer process is almost $100 \%$ reversible. This makes it possible to record spectra for different delay time settings between laser pulse and microwave pulse over an extended period of time. The spectra exhibit a fast rise and decay time. Additional measurements are required before a complete interpretation of the data can be given. 
A second set of measurements focused on the reaction between photo-excited benzophenone and iso-propanol in which a hydrogen atom is transferred from the alcohol to benzophenone giving two ketyl radicals. This system gives rise to strong FT EPR spectra as well. However, since the reaction is not reversible, some method of sample replenishment must be used to make it possible to generate a series of time resolved spectra.

The initial results of this work look very promising. In the coming months we will complete the analysis of the measurements carried out so far. The study will be extended to systems in which photochemistry takes place between adsorbed molecules and molecules in solution. 


\section{PUBLICATIONS}

G. Kroll, M. Plüschau, K. P. Dinse, H. van Willigen, "FOURIER TRANSFORM ELECTRON PARAMAGNETIC RESONANCE SPECTROSCOPY OF CORRELATED RADICAL PAIRS", J. Chem. Phys. 1990, 93, 8709-8716.

P. R. Levstein, H. van Willigen, M. Ebersole, and F. W. Pijpers, "FT-EPR STUDY OF PHOTOINDUCED ELECTRON TRAiNSFER IN A MICELLAR SYSTEM", Mol. Cryst. Liq. Cryst. 1991, 194, 123-131.

P. R. Levstein and H. van Willigen, "FOURIER TRANSFORM ELECTRON PARAMAGNETIC RESONANCE STUDY OF THE PHOTOCHEMICAL REACTION OF ACETONE WITH 2-PROPANOL" J. Chem. Phys. 1991, 95, 900-908.

D. Reddy, N. S. Reddy, T. K. Chandrashekar, and H. van Willigen, "OXIDATION OF Co(II) TETRAPYRROLES IN THE PRESENCE OF AN ELECTRON ACCEPTOR" J. Chem. Soc. Dalton Trans. 1991, 2097-2101.

H. van Willigen, P. R. Levstein, and M. H. Ebersole, "FOURIER TRANSFORM EPR STUDIES OF PHOTOCHEMICAL REACTIONS" in Mugnetic Resonance: current trends, C. L. Khetrapal and G. Govil eds., Narosa Publishing House 1991, 333-351. H. van Willigen, "CURRENT TF'ENDS IN EPR SPECTROSCOPY" Current Science 1991, 61, 95-97.

P. R. Levstein and H. van Willigen, "PHOTOINDUCED ELECTRON TRANSFER FROM PORPHYRINS TO QUINONES IN MICELLAR SYSTEMS: AN FT-EPR STL DY" Chem. Phys. Leit. 1991, 187, 415-422.

P. R. Levstein, M. H. Ebersole, and H. van Willigen, "FOURIER TRANSFORM EPR STUDIES OF PHOTOINDUCED ELECTRON TRANSFER IN HOMOGENEOUS AND MICELLAR SOLUTIONS" Proc. Indian Acad. Sc. 1992, in press. 

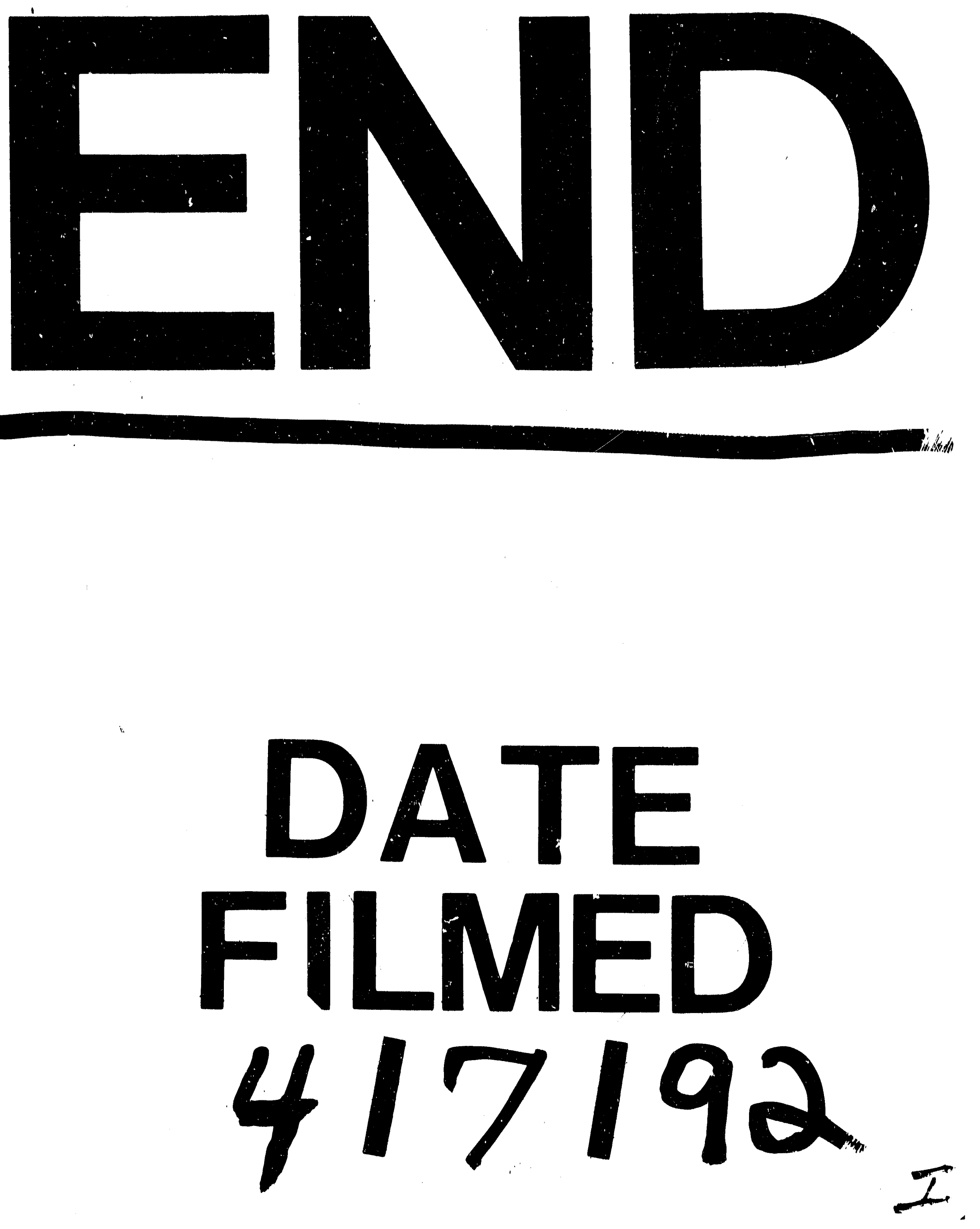
